\title{
Association Between Postpartum High B-Hydroxybutyrate and/or Non-Esterified Fatty Acids and Plasma Metabolites, Body Condition and Reproductive Performance in Dairy Cows
}

\author{
Kalem Ammar ${ }^{1}$, Abdelli Amine ${ }^{1 *}$, Raboisson Didier ${ }^{2}$ and Kaidi Rachid ${ }^{1}$ \\ ${ }^{1}$ Institut des Sciences Vétérinaires (ISV) - Université Saad Dahlab Blida, Algérie \\ ${ }^{2}$ Université de Toulouse, France
}

Submission: December 12, 2017; Published: February 02, 2018

*Corresponding author: Abdelli Amine, Institut des Sciences Vétérinaires, Université SAAD, Dahleb Blida (09000), Algérie, Tel: +213 551-167-056

; Email : abdelliamine@hotmail.fr

\begin{abstract}
The objectives were to assess post-partum blood non-esterified fatty acids (NEFA) and $\beta$ hydroxybutyrate (BHBA), considered either together or separately, relative to plasma metabolites, body condition score (BCS), estrus cyclicity and first service pregnancyin 50 dairy cows sampled from 15 to 52 days in milk (DIM).The thresholds for high NEFA and BHBA were $\geq 0.70 \mathrm{Mm}$ and $\geq 0.96 \mathrm{mM}$ at DIM 30 , respectively. Cows with simultaneously high BHBA and NEFA have different plasma metabolite profile compared to cows with low BHBA or NEFA and, to a lesser extent, compared to cows with high NEFA only. The change in BCS from calving to DIM 52 showed a similar pattern, with a more intensive BCS decrease in cases of high BHBA and NEFA, although the difference from cows with high NEFA only was not significant. Compared to cows with low BHBA and low NEFA, the odds of estrus cyclicity at DIM 52 was $85 \%$ lower in cases of high NEFA, and the odds of PRAI1 was $87 \%$ and $92.6 \%$ lower in cases of high BHBA or high NEFA, respectively. In conclusion, the present work demonstrates the added value of simultaneously measuring BHBA and NEFA, but new investigations are needed to explain the clinical outcomes linked to subclinical ketosis.
\end{abstract}

Keywords: BHB; NEAF; Plasma metabolites; BCS; Reproductive performance; Dairy cows

\section{Introduction}

Subclinical ketosis is a common disorder of dairy cows during peripartum. In the recent literature, $\beta$ hydroxybutyrate (BHBA) and non-esterified fatty acids (NEFA) have been used as markers of peripartum negative energy balance [1] or subclinical ketosis [2] There is evidence that these two markers cannot be used interchangeably [3]. In many studies, high pre- and postpartum NEFA or BHBA concentrations were the main risk factors for health disorders and poor reproductive performance (reviewed, for instance, by[2,4]. These studies considered only one of the biomarkers to evaluate subclinical ketosis or a highly negative energy balance. Recently, a weak relationship between the blood concentrations of NEFA and BHBA was reported [3], suggesting that high concentrations of one metabolite should not be extrapolated to high concentrations of the other. In most of the above mentioned studies, either postpartum NEFA or BHBA was retained in the final multi variable models, which means that these two metabolites overlap in the prediction of the outcome. However, a few examples suggest additive information between NEFA and BHBA. For instance, first-week postpartum NEFA and
BHBA levels above 0.96 and $1.2 \mathrm{mmol} / \mathrm{L}$ have been associated with an Odds Ratio of 6.3 and 4.7, respectively, for clinical ketosis in the same final multivariable model [5]. In a recent meta-analysis [4], cows with high post-partum NEFA were $32 \%$ less likely to conceive at first service (PR/IA) than were cows with high postpartum BHBA. The inclusion of the test (NEFA/ $\mathrm{BHBA}$ ) as a moderator in the meta-regression reduced the heterogeneity by $12 \%$. The meta-analysis also highlighted the weakness of epidemiological data on the association between reproduction performances and subclinical ketosis. The present study consequently aims to assess how high post-partum blood NEFA and BHBA levels, considered either separately or together, may improve the prediction of estrus cycling and first service pregnancy status (PRAI1) in dairy cows.

\section{Materials and Methods}

The animals, sampling methods and laboratory techniques have been described in detail in a companion paper [6]. Briefly, 50 Montbéliarde dairy cows producing an average of $25 \mathrm{~kg}$ milk/ 
day were enrolled. Cows were sampled fortnightly before the morning feeding on day in milk (DIM) 15, 30, 41, and 52. The BCS was evaluated on a half-point scale at calving (BCS-calv) and at each sampling. dBCS is the change in BCS from calving to week 4 postpartum. The serum BHBA concentration was measured using a hand-held meter (Optium Precision exceed, Abbott Laboratories, Abbott Park, IL, USA) at room temperature. Because of a lack of reagents, the plasma NEFA concentrations were measured only once at DIM 30 using the DVM-NEFA test (Veterinary Diagnostics, Newburg, WI, USA). The sensitivity and specificity were $85-90 \%$ and $94-98 \%$, respectively, for BHBA and $84 \%$ and $96 \%$, respectively, for NEFA. Cows were considered to have high NEFA and BHBA if the concentrations at DIM 30 were $\geq 0.70 \mathrm{mM}$ and $\geq 0.96 \mathrm{mM}$, respectively. Progesterone (P4) was measured by ELISA (Elecsys 2010, Roche Diagnostics GmBH, Mannheim, Germany). Pregnancy was diagnosed on day 30 after

\section{Results}

Table 1: Comparison of last square means and standard error (SE) of plasma constituents between cows having high or low NEFA and BHBA at DIM 15, 30, 41 and 52.

\begin{tabular}{|c|c|c|c|c|c|c|c|c|c|}
\hline \multirow[b]{2}{*}{ Metabolites } & \multirow[b]{2}{*}{ Group } & \multirow[b]{2}{*}{ SE } & \multicolumn{4}{|c|}{ Last Square Means } & \multicolumn{3}{|c|}{ P Value } \\
\hline & & & DIM 52 & DIM41 & DIM30 & DIM 15 & $\begin{array}{c}\text { Group* } \\
\text { Time }\end{array}$ & Time & Group \\
\hline \multirow{3}{*}{ Glucose } & $\begin{array}{l}\text { High NEFA } \\
\text { and BHBA }\end{array}$ & 0.031 & 0.655 & 0.657 & 0.652 & 0.651 & \multirow{3}{*}{0.988} & \multirow{3}{*}{0.009} & \multirow{3}{*}{0.951} \\
\hline & High NEFA & 0.029 & 0.668 & 0.669 & 0.666 & 0.664 & & & \\
\hline & $\begin{array}{l}\text { Low NEFA } \\
\text { and BHBA }\end{array}$ & 0.026 & 0.663 & 0.664 & 0.66 & 0.656 & & & \\
\hline \multirow{3}{*}{ Cholesterol } & $\begin{array}{l}\text { High NEFA } \\
\text { and BHBA }\end{array}$ & 0.091 & $1.799 a$ & $1.792 \mathrm{a}$ & $1.777 \mathrm{a}$ & 1.743 & \multirow{3}{*}{0.657} & \multirow{3}{*}{$<0.001$} & \multirow{3}{*}{0.149} \\
\hline & High NEFA & 0.11 & $1.632 \mathrm{ab}$ & $1.620 \mathrm{ab}$ & $1.616 \mathrm{ab}$ & 1.589 & & & \\
\hline & $\begin{array}{l}\text { Low NEFA } \\
\text { and BHBA }\end{array}$ & 0.105 & $1.526 \mathrm{~b}$ & $1.525 \mathrm{~b}$ & $1.513 \mathrm{~b}$ & 1.495 & & & \\
\hline \multirow{3}{*}{ Triglycerides } & $\begin{array}{l}\text { High NEFA } \\
\text { and BHBA }\end{array}$ & 0.016 & $0.215 a$ & $0.213 \mathrm{a}$ & $0.214 \mathrm{a}$ & $0.216 \mathrm{a}$ & \multirow{3}{*}{0.885} & \multirow{3}{*}{0.869} & \multirow{3}{*}{0.083} \\
\hline & High NEFA & 0.015 & $0.176 a b$ & $0.175 a b$ & $0.176 a b$ & $0.175 \mathrm{ab}$ & & & \\
\hline & $\begin{array}{l}\text { Low NEFA } \\
\text { and BHBA }\end{array}$ & 0.014 & $0.166 \mathrm{~b}$ & $0.168 \mathrm{~b}$ & $0.169 \mathrm{~b}$ & $0.171 \mathrm{~b}$ & & & \\
\hline \multirow{3}{*}{ Urea } & $\begin{array}{l}\text { High NEFA } \\
\text { and BHBA }\end{array}$ & 0.026 & $0.354 a$ & $0.347 a$ & $0.351 \mathrm{a}$ & 0.344 & \multirow{3}{*}{0.422} & \multirow{3}{*}{0.199} & \multirow{3}{*}{0.171} \\
\hline & High NEFA & 0.031 & $0.308 \mathrm{~b}$ & $0.305 \mathrm{ab}$ & $0.305 \mathrm{ab}$ & 0.306 & & & \\
\hline & $\begin{array}{l}\text { Low NEFA } \\
\text { and BHBA }\end{array}$ & 0.033 & $0.271 b$ & $0.272 \mathrm{~b}$ & $0.275 b$ & 0.271 & & & \\
\hline \multirow{3}{*}{$\begin{array}{c}\text { Aspartate } \\
\text { aminotransferase }\end{array}$} & $\begin{array}{l}\text { High NEFA } \\
\text { and BHBA }\end{array}$ & 5.624 & 104.43 & $104.85 a$ & $99.21 \mathrm{a}$ & $97.93 a$ & \multirow{3}{*}{0.799} & \multirow{3}{*}{0.681} & \multirow{3}{*}{0.519} \\
\hline & High NEFA & 4.646 & 96.58 & $82.14 \mathrm{~b}$ & $84.88 \mathrm{~b}$ & $85.23 \mathrm{~b}$ & & & \\
\hline & $\begin{array}{l}\text { Low NEFA } \\
\text { and BHBA }\end{array}$ & 3.643 & 84.39 & $80.50 \mathrm{~b}$ & $84.05 b$ & 91.27ab & & & \\
\hline \multirow{3}{*}{$\begin{array}{c}\text { Alanine } \\
\text { aminotransferase }\end{array}$} & $\begin{array}{l}\text { High NEFA } \\
\text { and BHBA }\end{array}$ & 2.858 & 38.279 & $38.932 \mathrm{a}$ & 37.738 & 36.973 & \multirow{3}{*}{0.239} & \multirow{3}{*}{$<0.001$} & \multirow{3}{*}{0.373} \\
\hline & High NEFA & 3.495 & 35.315 & $35.199 \mathrm{~b}$ & 34.904 & 34.422 & & & \\
\hline & $\begin{array}{l}\text { Low NEFA } \\
\text { and BHBA }\end{array}$ & 3.324 & 40.572 & $40.036 \mathrm{~b}$ & 39.963 & 39.459 & & & \\
\hline
\end{tabular}
visualizing alive embryo. Pregnancy was confirmed systematically by transrectal palpation 35 days later. The presence of an active corpus luteum was defined as P4 concentrations above 1ng/ mLat DIM 52.

Statistical analyses were performed with SAS (Version 9.1.3; SAS Institute Inc., Cary, NC, USA). First, the concentrations of metabolites were analysed as repeated measures using a mixed model procedure with cow as random variable (PROC MIXED). Second, the same procedure was applied to BCS, and dBCS was analyzed with a linear model. Third, the sensitivity, specificity and accuracy of high BHBA, high NEFA or high BHBA and NEFA for detecting cows with estrus cyclicity and pregnancy were calculated using Win Episcope 2.0 (Ignacio de Blas, university of Zaragoza, Zaragoza, Spain)
AI via transrectal ultrasonography and was characterized by 
The overall incidence of cows with high BHBA or high NEFA at DIM30 was $30 \%$ and $62 \%$, respectively. All cows except one (93.33\%) with high BHBA at DIM 30 also had high NEFA. Compared to cows with low NEFA and BHBA, cows with high NEFA and BHBA at DIM 30 had significantly higher cholesterol at DIM 30, 41 and 52, higher triglycerides from DIM 15 to DIM 52, higher urea from DIM 30 to DIM 52, higher aspartate aminotransferase (ASAT) at DIM 30 and DIM 41 and higher alanine aminotransferase (ALAT) at DIM 41 (Table 1). For these metabolite types and days, the metabolite concentrations were higher for cows with high NEFA compared to cows with low NEFA and BHBA, but these differences were not significant. Compared to cows with high NEFA only, cows with high NEFA and BHBA had significantly higher urea at DIM 52, higher ASAT from DIM 15 to DIM 41 and higher ALAT at DIM 41. When considering each model (i.e., each metabolite) as a whole, alpha value was high for the group effect, the time effect and the interaction.
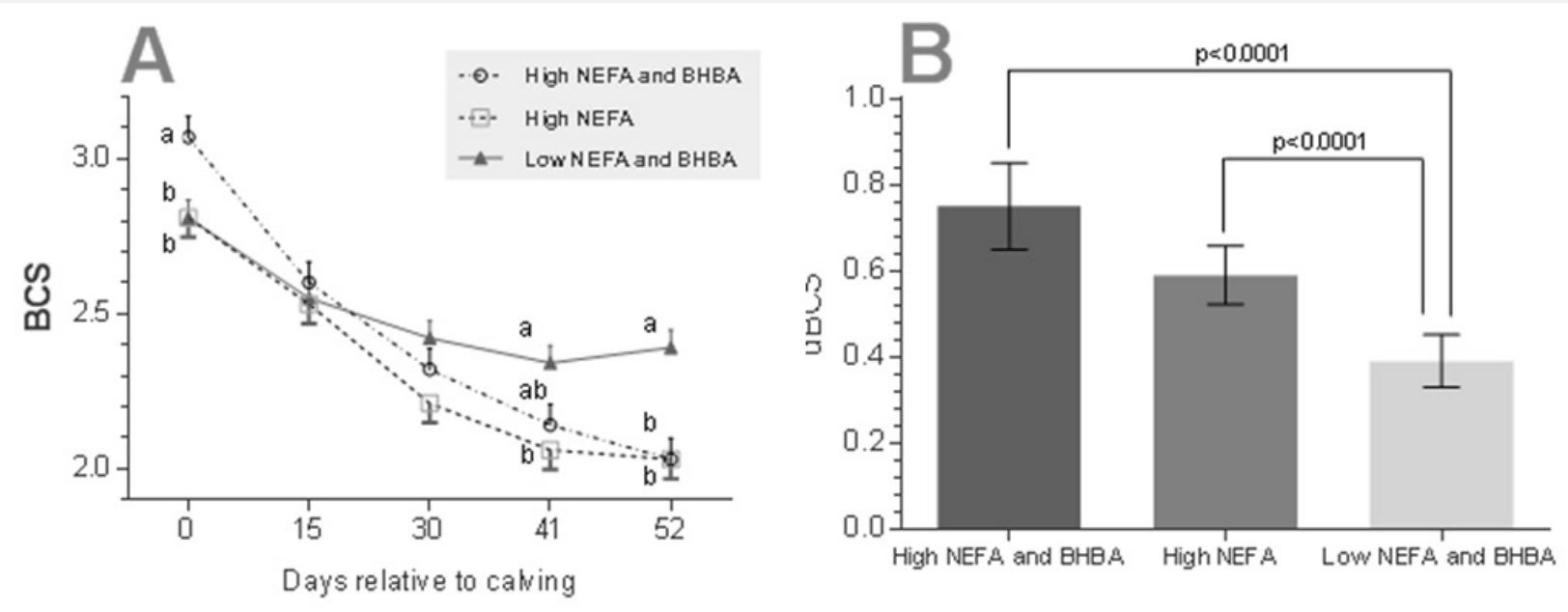

Figure 1: Least square means \pm SEM for $B C S$ at calving, DIM 15, 30, 41 and $52(A)$ and $B C S$ change (dBCS, means $\pm S E M)$ from calving to DIM 30 for cows with high NEFA, high NEFA and BHBA, or low NEFA and BHBA.

The repeated measure ANOVA with the mixed model revealed a significant group effect $(\mathrm{P}=0.01)$, time effect $(\mathrm{P}<0.0001)$ and group-by-time interaction $(\mathrm{P}<0.0001)$ for $\mathrm{BCS}$. Cows with high NEFA and BHBA had a significantly higher BCS at calving compared to the other groups and a significantly lower BCS at DIM 52 compared to cows with low BHBA and NEFA (Figure 1A). Cows with high NEFA and BHBA had a lower BCS at DIM 41 and 52 compared to cows with no change in BHBA or NEFA. Because BCS at calving differed between groups, we focused on dBCS. dBCS was higher in cows with high NEFA and BHBA

Table 2. Test performances and odds of estrus cyclicity or pregnancy at first AI (PRAI1) for high BHBA alone, high NEFA alone or both high BHBA and NEFA.

\begin{tabular}{|c|c|c|c|c|c|c|}
\hline Test & Cows with outcome & Sensitivity (95\%CI) & Specificity (95\%CI) & Accuracy & OR $(95 \% \mathrm{CI})$ & P-value \\
\hline \multicolumn{7}{|c|}{ Anestrus cows } \\
\hline High BHBA & Aug-15 & $36.4 \%(16.3-56.5)$ & $75.00 \%(59.0-91.0)$ & $58.00 \%$ & $0.155(0.02-1.12)$ & 0.064 \\
\hline High NEFA & $18 / 31$ & $81.8 \%(65.7-97.9)$ & $53.60 \%(35.1-72.0)$ & $66.00 \%$ & $0.107(0.02-0.53)$ & 0.006 \\
\hline $\begin{array}{l}\text { High BHBA and } \\
\text { NEFA }\end{array}$ & Jul-14 & $70.0 \%(41.6-98.4)$ & $69.60 \%(50.8-88.4)$ & $69.70 \%$ & $1.451(0.23-9.41)$ & 0.695 \\
\hline \multicolumn{7}{|c|}{ Pregnancy to first AI } \\
\hline High BHBA & $13 / 15$ & $46.4 \%(28.0-64.9)$ & $90.90 \%(78.9-102.9)$ & $66.00 \%$ & $0.13(0.04-0.46)$ & 0.001 \\
\hline High NEFA & $28 / 31$ & $84.8 \%(72.6-97.1)$ & $82.40 \%(64.2-100.5)$ & $84.00 \%$ & $0.074(0.01-0.48)$ & 0.006 \\
\hline $\begin{array}{l}\text { High BHBA and } \\
\text { NEFA }\end{array}$ & Dec-14 & $75.0 \%(53.8-96.2)$ & $88.2 \%(72.9-103.6)$ & $81.80 \%$ & $1.739(0.16-18.7)$ & 0.647 \\
\hline
\end{tabular}

compared to high NEFA only or low BHBA and NEFA, but the difference between high BHBA and NEFA or high NEFA only was not significant (Figure 1B).

The proportion of cows with serum P4>1ng/mL was $56 \%$ at 52 DIM, and the PR/AI at first insemination was $34 \%$. Using high NEFA instead of high BHBA increased the sensitivity, decreased the specificity and increased the accuracy for both outcomes. Using high BHBA and NEFA instead of high NEFA alone reduced the sensitivity and increased the specificity but only increased the accuracy for estrus cyclicity. 
The odds of estrus cyclicity at DIM 52 were $85 \%$ lower $(\mathrm{OR}=0.155, \mathrm{P}=0.006)$ in cases of high NEFA compared to cows with low BHBA and NEFA. No significant association was detected for other classes. Thus, considering BHBA alone or both BHBA and NEFA reduced the ability to predict estrus cyclicity at 52 DIM compared to using NEFA only (Table 2).

The odds of PRAI 1 at 65 DIM were $87 \%$ lower (OR=0.13, $\mathrm{P}=0.001)$ in cases of high BHBA compared to cows with low BHBA and NEFA and $92.6 \%$ lower $(\mathrm{OR}=0.074, \mathrm{P}=0.006)$ in cases of high NEFA compared to cows with low BHBA and NEFA. Considering both BHBA and NEFA reduced the ability to explain PRAI at 52 DIM compared to high BHBA alone or high NEFA alone.

\section{Discussion}

The present work clearly highlights that the simultaneous measurement of BHBA and NEFA may provide increased information regarding a cow's metabolic status. It clearly shows that cows with simultaneously high BHBA and NEFA have different plasma metabolite profiles than do cows with low BHBA and NEFA and, to a lesser extent, than do cows with high NEFA only. It demonstrates the added value of simultaneously measuring BHBA and NEFA. The change in BCS shows similar trends, with a higher decrease in BCS in the case of high BHBA and NEFA compared to high NEFA only, although the difference was not significant. Finally, the simultaneous measurement of NEFA and BHBA has not been identified as a predictor for estrus cyclicity or PRAI1, and the added value compared to NEFA or BHBA alone seems null. This may be due to the late measurement of NEFA or BHBA (DIM30).

The changes in blood metabolites or BCS in cases of subclinical ketosis (defined as high NEFA or BHBA alone or high BHBA and NEFA) are largely in agreement with the existing literature [7] for instance, except for glucose [8]. The present work also brings additional data to the link between subclinical ketosis and estrus cyclicity or PRAI1, with a precise quantification of the associations between them. These quantifications have been reported to be scarce [4]. The impairment of estrus cyclicity or PRAI1 reported here is higher than that reported in previous results [4], suggesting a high impact of sub clinical ketosis on reproduction performance. However, the observed high impact may be due in part to the late measurement of BHBA and NEFA (DIM30) compared to previous studies.

\section{Conclusion}

The present work demonstrates the added value of simultaneously measuring BHBA and NEFA to characterize sub clinical ketosis severity, which is defined as a change in blood metabolites and BCS. New investigations are needed to link the dynamics of ketones and NEFA with clinical outcomes.

\section{References}

1. Duffield TF, Lissemore KD, McBride BW, Leslie KE (2009) Impact of hyperketonemia in early lactation dairy cows on health and production. J Dairy Sci 92(2): 571-580.

2. Raboisson D, Mounié M, Maigné E (2014) Diseases, reproductive performance, ajhhnd changes in milk production associated with subclinical ketosis in dairy cows: a meta-analysis and review. J Dairy Sci 97 (12) 7547-7563.

3. McCarthy MM, Mann S, Nydam DV, Overton TR, McArt JAA (2015) Short communication: Concentrations of non esterified fatty acids and $\beta$-hydroxy butyrate in dairy cows are not well correlated during the transition period. J Dairy Sci 98(9): 6284-6290.

4. Abdelli A, Raboisson D, Ibrahim B, Kalem A, Kaidi R, et al. (2017) Elevated non-esterified fatty acid and $\beta$-hydroxybutyrate in transition dairy cows and their association with reproductive performance and disorders: A meta-analysis. Theriogenology 93: 99-104.

5. Seifi HA, LeBlanc SJ, Leslie KE, Duffield TF (2011) Metabolic predictors of post-partum disease and culling risk in dairy cattle. Vet J 188: 216220.

6. Kalem A, Hanzen C, Abdelli A, Kaidi R (2017) Body condition score, some nutritional parameters in plasma, and subsequent reproductive performance of Montbéliarde cows in Algeria. Livestock Research for Rural Development 29(1).

7. Shin EK, Jeong JK, Choi IS, Kang HG, Hur TY, et al. (2015) Relationships among ketosis, serum metabolites, body condition, and reproductive outcomes in dairy cows. Theriogenology 84(2):252-260.

8. Jorritsma R, Jorritsma H, Schukken YH, Bartlett PC, et al. (2001) Prevalence and indicators of post-partum fatty infiltration of the liver in nine commercial dairy herds in The Netherlands. Livestock Production Science 68(1):53-60.

\section{Your next submission with Juniper Publishers} will reach you the below assets

- Quality Editorial service

- Swift Peer Review

- Reprints availability

- E-prints Service

- Manuscript Podcast for convenient understanding

- Global attainment for your research

- Manuscript accessibility in different formats ( Pdf, E-pub, Full Text, Audio)

- Unceasing customer service

Track the below URL for one-step submission https://juniperpublishers.com/online-submission.php 